\title{
Publication List of Zoltán Ésik
}

\section{Books}

[1] Zoltán Ésik. Modern Automata Theory, Russian translation: Covremennaja Teoria Avtomatovm Kaliningrad. Technische Universität Wien, 2007.

[2] Stephen L. Bloom and Zoltán Ésik. Iteration Theories - The Equational Logic of Iterative Processes. EATCS Monographs on Theoretical Computer Science. Springer, 1993.

\section{Book chapters}

[1] Equational theories for automata. In Handbook of Automata. EMS Publishing House, to appear.

[2] Zoltán Ésik. Fixed point theory. In Handbook of Weighted Automata, pages 29-65. Springer Berlin Heidelberg, Berlin, Heidelberg, 2009.

[3] Zoltán Ésik and Werner Kuich. Finite automata. In Handbook of Weighted Automata, pages 69-104. Springer Berlin Heidelberg, Berlin, Heidelberg, 2009.

[4] Zoltán Ésik. Automata theory. In Encyclopedia of Computer Science and Technology, pages 9-36. Marcel Dekker Inc., New York, 1991.

\section{Edited volumes}

[1] Zoltán Ésik and Martin Dietzfelbinger, editors. Mathematical Foundations of Computer Science 2014, Special Issue, Information and Computation, to appear.

[2] Zoltán Ésik and Zoltán Fülöp, editors. Automata and Formal Languages: Special Issue AFL 2014, volume 26(8) of International Journal of Foundations of Computer Science. World Scientific, 2015. 
[3] Erzsébet Csuhaj-Varjú, Martin Dietzfelbinger, and Zoltán Ésik, editors. Mathematical Foundations of Computer Science 2014 - 39th International Symposium, MFCS 2014, Budapest, Hungary, August 25-29, 2014. Proceedings, Part I, volume 8634 of Lecture Notes in Computer Science. Springer, 2014.

[4] Erzsébet Csuhaj-Varjú, Martin Dietzfelbinger, and Zoltán Ésik, editors. Mathematical Foundations of Computer Science 2014 - 39th International Symposium, MFCS 2014, Budapest, Hungary, August 25-29, 2014. Proceedings, Part II, volume 8635 of Lecture Notes in Computer Science. Springer, 2014.

[5] Zoltán Ésik and Zoltán Fülöp, editors. Proceedings 14th International Conference on Automata and Formal Languages, AFL 2014, Szeged, Hungary, May 27-29, 2014, volume 151 of EPTCS, 2014.

[6] Dale Miller and Zoltán Ésik, editors. Proceedings 8th Workshop on Fixed Points in Computer Science, FICS 2012, Tallinn, Estonia, 24th March 2012, volume 77 of EPTCS, 2012.

[7] Pál Dömösi and Zoltán Ésik, editors. Proceedings 13th International Conference on Automata and Formal Languages, AFL 2011, volume 23 of Int. J. Found. Comput. Sci., 2012.

[8] Erzsébet Csuhaj-Varjú and Zoltán Ésik, editors. Fundamentals of Computation Theory. Special issue devoted to papers presented at FCT 0\%, volume 411 of Theor. Comput. Sci., 2010.

[9] Erzsébet Csuhaj-Varjú and Zoltán Ésik, editors. Automata and Formal Languages: Special Issue AFL 2008, volume 21 of Int. J. Found. Comput. Sci., 2010.

[10] Erzsébet Csuhaj-Varjú and Zoltán Ésik, editors. Automata and Formal Languages, volume 19 of Acta Cybern., 2009.

[11] Zoltán Ésik and Zoltán Fülöp, editors. Automata, Formal Languages, and Related Topics - Dedicated to Ferenc Gécseg on the occasion of his 70th birthday. Institute of Informatics, University of Szeged, Hungary, 2009.

[12] Erzsébet Csuhaj-Varjú and Zoltán Ésik, editors. Automata and Formal Languages, 12th International Conference, AFL 2008, Balatonfüred, Hungary, May 27-30, 2008, Proceedings, 2008.

[13] Erzsébet Csuhaj-Varjú and Zoltán Ésik, editors. Fundamentals of Computation Theory, 16th International Symposium, FCT 2007, Budapest, Hungary, August 27-30, 2007, Proceedings, volume 4639 of Lecture Notes in Computer Science. Springer, 2007.

[14] Zoltán Ésik and R. Ramanujam, editors. Selected Papers of the Conference "Computer Science Logic 2006", number 4 in LMCS, 2006. 
[15] Zoltán Ésik, editor. Automata and Formal Languages: Special Issue of AFL 2005, volume 17(4) of Acta Cybern., 2006.

[16] Zoltán Ésik, editor. Automata and Formal Languages: Special Issue of AFL 2005, volume 366(3) of Theor. Comput. Sci., 2006.

[17] Zoltán Ésik, editor. Computer Science Logic, 20th International Workshop, CSL 2006, 15th Annual Conference of the EACSL, Szeged, Hungary, September 25-29, 2006, Proceedings, volume 4207 of Lecture Notes in Computer Science. Springer, 2006.

[18] Zoltán Ésik, Carlos Martín-Vide, and Victor Mitrana, editors. Recent Advances in Formal Languages and Applications, volume 25 of Studies in Computational Intelligence. Springer, 2006.

[19] Alberto Bertoni, Zoltán Ésik, and Juhani Karhumäki, editors. The art of rationality: In honour of Professor Christian Choffrut on the occasion of his 60th birthday. Theor. Comput. Sci. Elsevier, 2006.

[20] Zoltán Ésik, editor. Automata and Formal Languages (AFL '05). Acta Cybern. University of Szeged, 2006.

[21] Luca Aceto, Wan Fokkink, Anna Ingólfsdóttir, and Zoltán Ésik, editors. Process Algebra, Special Issue, volume 335(2-3) of Theor. Comput. Sci., 2005.

[22] Zoltán Ésik and Zoltán Fülöp, editors. Automata and Formal Languages: 11th International Conference, AFL 2005. University of Szeged, 2005.

[23] Zoltán Ésik and Igor Walukiewicz, editors. Fixed Points in Computer Science 03, Warsaw, Special issue, volume 38(4) of ITA, 2004.

[24] Luca Aceto, Wan Fokkink, Anna Ingólfsdóttir, and Zoltán Ésik, editors. Workshop on Process Algebra: Open Problems and Future Directions, PA '03, (Bologna, Italy, 21-25 July, 2003), volume NS 03-3 of BRICS Notes Series, 2003.

[25] Zoltán Ésik and Anna Ingólfsdóttir, editors. Fixed Points in Computer Science 02, Copenhagen, Special issue, volume 37 of ITA, 2003.

[26] Zoltán Ésik and Zoltán Fülöp, editors. Developments in Language Theory, 7th International Conference, DLT 2003, Szeged, Hungary, July 7-11, 2003, Proceedings, volume 2710 of Lecture Notes in Computer Science. Springer, 2003.

[27] Zoltán Ésik and Anna Ingólfsdóttir, editors. Fixed Points in Computer Science, FICS 2002, Copenhagen, Denmark, 20-21 July 2002, Preliminary Proceedings, volume NS-02-2 of BRICS Notes Series. University of Aarhus, 2002. 
[28] János Csirik, Zoltán Ésik, Zoltán Fülöp, and Balázs Imreh, editors. Special issue dedicated to the 60th birthday of Prof. Ferenc Gecseg, volume 14 of Acta Cybern., 1999.

[29] Zoltán Ésik, editor. Proceedings Workshop on Fixed Points in Computer Science, FICS, volume 33 of Theoretical Infomatics and Applications, 1999.

[30] Zoltán Ésik (editor). Számítási bonyolultság. Novadat, 1999.

[31] Zoltán Ésik, editor. Fundamentals of Computation Theory, 9th International Symposium, FCT '93, Szeged, Hungary, August 23-27, 1993, Proceedings, volume 710 of Lecture Notes in Computer Science. Springer, 1993.

[32] Zoltán Ésik (editor). Számok valóson innen és túl. Gondolat, Budapest, 1987.

\section{Refereed journal articles}

[1] Zoltán Ésik. Equational axioms associated with finite automata for fixed point operations in Cartesian categories. Mathematical Structures in Computer Science, 27(1):54-69, 2017.

[2] Arnaud Carayol and Zoltán Ésik. An analysis of the equational properties of the well-founded fixed point. J. Log. Algebr. Meth. Program., 86(1):308-318, 2017.

[3] Zoltán Ésik. Residuated Park theories. J. Log. Comput., 25(2):453-471, 2015.

[4] Zoltán Ésik and Panos Rondogiannis. A fixed point theorem for nonmonotonic functions. Theor. Comput. Sci., 574:18-38, 2015.

[5] Manfred Droste, Zoltán Ésik, and Werner Kuich. Conway and iteration hemirings Part 1. IJAC, 24(4):461-482, 2014.

[6] Manfred Droste, Zoltán Ésik, and Werner Kuich. Conway and iteration hemirings Part 2. IJAC, 24(4):483-514, 2014.

[7] Zoltán Ésik and Szabolcs Iván. Operational characterization of scattered MCFLs. Int. J. Found. Comput. Sci., 25(8):1001-1016, 2014.

[8] Zoltán Ésik and Tamás Hajgató. On the structure of free iteration semirings. Journal of Automata, Languages and Combinatorics, 19(1-4):57-66, 2014.

[9] Zoltán Ésik. Axiomatizing weighted synchronization trees and weighted bisimilarity. Theor. Comput. Sci., 534:2-23, 2014.

[10] Angelos Charalambidis, Zoltán Ésik, and Panos Rondogiannis. Minimum model semantics for extensional higher-order logic programming with negation. TPLP, 14(4-5):725-737, 2014. 
[11] Zoltán Ésik and Satoshi Okawa. On context-free languages of scattered words. Int. J. Found. Comput. Sci., 24(7):1029-1048, 2013.

[12] Arnaud Carayol and Zoltán Ésik. The FC-rank of a context-free language. Inf. Process. Lett., 113(8):285-287, 2013.

[13] Zoltán Ésik and Werner Kuich. Free inductive $K$-semialgebras. J. Log. Algebr. Program., 82(3-4):111-122, 2013.

[14] Zoltán Ésik. Ordinal automata and Cantor normal form. Int. J. Found. Comput. Sci., 23(1):87-98, 2012.

[15] Zoltán Ésik and Szabolcs Iván. On Müller context-free grammars. Theor. Comput. Sci., 416:17-32, 2012.

[16] Zoltán Ésik and Werner Kuich. Free iterative and iteration $K$-semialgebras. Algebra Universalis, 67:141-162, 2012.

[17] Stephen L. Bloom and Zoltán Ésik. Algebraic linear orderings. Int. J. Found. Comput. Sci., 22(2):491-515, 2011.

[18] Zoltán Ésik and Andreas Maletti. The category of simulations for weighted tree automata. Int. J. Found. Comput. Sci., 22(8):1845-1859, 2011.

[19] Zoltán Ésik. An undecidable property of context-free linear orders. Inf. Process. Lett., 111(3):107-109, 2011.

[20] Zoltán Ésik and Tamás Hajgató. Dagger extension theorem. Mathematical Structures in Computer Science, 21(5):1035-1066, 2011.

[21] Zoltán Ésik and Szabolcs Iván. Büchi context-free languages. Theor. Comput. Sci., 412(8-10):805-821, 2011.

[22] Stephen L. Bloom and Zoltán Ésik. Algebraic ordinals. Fundam. Inform., 99(4):383-407, 2010.

[23] Zoltán Ésik and Pascal Weil. Algebraic characterization of logically defined tree languages. IJAC, 20(2):195-239, 2010.

[24] Zoltán Ésik. Axiomatizing the equational theory of regular tree languages. J. Log. Algebr. Program., 79(2):189-213, 2010.

[25] Stephen L. Bloom and Zoltán Ésik. A Mezei-Wright theorem for categorical algebras. Theor. Comput. Sci., 411(2):341-359, 2010.

[26] Zoltán Ésik and Szabolcs Iván. A family of temporal logics on finite trees. Publ. Math. Debrecen, 77(3-4):277-297, 2010.

[27] Stephen L. Bloom and Zoltán Ésik. Axiomatizing rational power series over natural numbers. Inf. Comput., 207(7):793-811, 2009. 
[28] Zoltán Ésik, Yuan Gao, Guangwu Liu, and Sheng Yu. Estimation of state complexity of combined operations. Theor. Comput. Sci., 410(35):3272-3280, 2009.

[29] Zoltán Ésik and Szabolcs Iván. Products of tree automata with an application to temporal logic. Fundam. Inform., 82(1-2):61-78, 2008.

[30] Zoltán Ésik and Szabolcs Iván. Some varieties of finite tree automata related to restricted temporal logics. Fundam. Inform., 82(1-2):79-103, 2008.

[31] Stephen L. Bloom, Zoltán Ésik, and Werner Kuich. Partial Conway and iteration semirings. Fundam. Inform., 86(1-2):19-40, 2008.

[32] Zoltán Ésik and Guangwu Liu. Fuzzy tree automata. Fuzzy Sets and Systems, 158(13):1450-1460, 2007.

[33] Zoltán Ésik and Werner Kuich. Boolean fuzzy sets. Int. J. Found. Comput. Sci., 18(6):1197-1207, 2007.

[34] Zoltán Ésik and Werner Kuich. A semiring-semimodule generalization of transducers and abstract $\omega$-families of power series. Journal of Automata, Languages and Combinatorics, 12(4):435-454, 2007.

[35] Zoltán Ésik and Werner Kuich. On iteration semiring-semimodule pairs. Semigroup Forum, 75:129-159, 2007.

[36] Zoltán Ésik. Characterizing CTL-like logics on finite trees. Theor. Comput. Sci., 356(1-2):136-152, 2006.

[37] Zoltán Ésik and Hans Leiß. Algebraically complete semirings and Greibach normal form. Ann. Pure Appl. Logic, 133(1-3):173-203, 2005.

[38] Stephen L. Bloom and Zoltán Ésik. The equational theory of regular words. Inf. Comput., 197(1-2):55-89, 2005.

[39] Zoltán Ésik and Zoltán L. Németh. Algebraic and graph-theoretic properties of infinite $n$-posets. ITA, 39(1):305-322, 2005.

[40] Zoltán Ésik and Werner Kuich. A semiring-semimodule generalization of $\omega$ regular languages I. Journal of Automata, Languages and Combinatorics, 10(2/3):203-242, 2005.

[41] Zoltán Ésik and Werner Kuich. A semiring-semimodule generalization of $\omega$ regular languages II. Journal of Automata, Languages and Combinatorics, 10(2/3):243-264, 2005.

[42] Zoltán Ésik and Pascal Weil. Algebraic recognizability of regular tree languages. Theor. Comput. Sci., 340(1):291-321, 2005.

[43] Stephen L. Bloom and Zoltán Ésik. Axiomatizing $\omega$ and $\omega$-op powers of words. ITA, 38(1):3-17, 2004. 
[44] Zoltán Ésik and Zoltán L. Németh. Higher dimensional automata. Journal of Automata, Languages and Combinatorics, 9(1):3-29, 2004.

[45] Zoltán Ésik and Werner Kuich. Inductive star-semirings. Theor. Comput. Sci., 324(1):3-33, 2004.

[46] Zoltán Ésik and Masami Ito. Temporal logic with cyclic counting and the degree of aperiodicity of finite automata. Acta Cybern., 16(1):1-28, 2003.

[47] Janusz A. Brzozowski and Zoltán Ésik. Hazard algebras. Formal Methods in System Design, 23(3):223-256, 2003.

[48] Stephen L. Bloom and Zoltán Ésik. Deciding whether the frontier of a regular tree is scattered. Fundam. Inform., 55(1):1-21, 2003.

[49] Zoltán Ésik and Kim Guldstrand Larsen. Regular languages definable by Lindström quantifiers. ITA, 37(3):179-241, 2003.

[50] Stephen L. Bloom and Zoltán Ésik. An extension theorem with an application to formal tree series. Journal of Automata, Languages and Combinatorics, $8(2): 145-185,2003$.

[51] Zoltán Ésik and Werner Kuich. Formal tree series. Journal of Automata, Languages and Combinatorics, 8(2):219-285, 2003.

[52] Luca Aceto, Zoltán Ésik, and Anna Ingólfsdóttir. Equational theories of tropical semirings. Theor. Comput. Sci., 3(298):417-469, 2003.

[53] Luca Aceto, Zoltán Ésik, and Anna Ingólfsdóttir. The max-plus algebra of the natural numbers has no finite equational basis. Theor. Comput. Sci., 293(1):169-188, 2003.

[54] Zoltán Ésik. Free De Morgan bisemigroups and bisemilattices. Algebra Colloquium, 10:23-32, 2003.

[55] Luca Aceto, Zoltán Ésik, and Anna Ingólfsdóttir. A fully equational proof of Parikh's theorem. ITA, 36(2):129-153, 2002.

[56] Zoltán Ésik and Werner Kuich. Rationally additive semirings. J. UCS, 8(2):173-183, 2002.

[57] Zoltán Ésik. Continuous additive algebras and injective simulations of synchronization trees. J. Log. Comput., 12(2):271-300, 2002.

[58] Zoltán Ésik. Axiomatizing the subsumption and subword preorders on finite and infinite partial words. Theor. Comput. Sci., 273(1-2):225-248, 2002.

[59] Z. Ésik and W. Kuich. Locally closed semirings. Monatshefte für Mathematik, 137(1):21-29, 2002. 
[60] Pál Dömösi and Zoltán Ésik. A note on completeness of the $\nu_{3}$-product. Publ. Math. Debrecen, 60:539-550, 2002.

[61] Stephen L. Bloom, Zoltán Ésik, Anna Labella, and Ernest G. Manes. Iteration 2-theories. Applied Categorical Structures, 9(2):173-216, 2001.

[62] Sinisa Crvenkovic, Igor Dolinka, and Zoltán Ésik. On equations for union-free regular languages. Inf. Comput., 164(1):152-172, 2001.

[63] Pál Dömösi and Zoltán Ésik. Homomorphic simulation and Letichevsky's criterion. Journal of Automata, Languages and Combinatorics, 6(4):427-436, 2001.

[64] Zoltán Ésik and Werner Kuich. A Kleene theorem for Lindenmayerian algebraic power series. Journal of Automata, Languages and Combinatorics, 5(2):109-122, 2000.

[65] Sinisa Crvenkovic, Igor Dolinka, and Zoltán Ésik. The variety of Kleene algebras with conversion is not finitely based. Theor. Comput. Sci., 230(12):235-245, 2000

[66] Zoltán Ésik. A proof of the Krohn-Rhodes decomposition theorem. Theor. Comput. Sci., 234(1-2):287-300, 2000.

[67] Zoltán Ésik. The power of the group-identities for iteration. IJAC, 10(3):349$374,2000$.

[68] Zoltán Ésik. Axiomatizing iteration categories. Acta Cybern., 14(1):65-82, 1999.

[69] Zoltán Ésik. Group axioms for iteration. Inf. Comput., 148(2):131-180, 1999.

[70] Sinisa Crvenkovic, Igor Dolinka, and Zoltán Ésik. A note on equations for commutative regular languages. Inf. Process. Lett., 70(6):265-267, 1999.

[71] Zoltán Ésik. A variety theorem for trees and theories. Publ. Math. Debrecen, 54:711-762, 1999.

[72] Zoltán Ésik and Michael Bertol. Nonfinite axiomatizability of the equational theory of shuffle. Acta Inf., 35(6):505-539, 1998.

[73] Zoltán Ésik. A Cayley theorem for ternary algebras. IJAC, 8(3):311-316, 1998.

[74] László Bernátsky and Zoltán Ésik. Semantics on flowchart programs and the free Conway theories. ITA, 32(1-3):35-78, 1998.

[75] Zoltán Ésik and Anna Labella. Equational properties of iteration in algebraically complete categories. Theor. Comput. Sci., 195(1):61-89, 1998. 
[76] Stephen L. Bloom and Zoltán Ésik. Shuffle binoids. RAIRO - Theoretical Informatics and Applications - Informatique Théorique et Applications, 32(46):175-198, 1998.

[77] Zoltán Ésik and Imre Simon. Modeling literal morphisms by shuffle. Semigroup Forum, 56(2):225-227, 1998.

[78] Stephen L. Bloom and Zoltán Ésik. Axiomatizing shuffle and concatenation in languages. Inf. Comput., 139(1):62-91, 1997.

[79] Stephen L. Bloom and Zoltán Ésik. Varieties generated by languages with poset operations. Mathematical Structures in Computer Science, 7(6):701$713,1997$.

[80] Zoltán Ésik. Completeness of Park induction. Theor. Comput. Sci., 177(1):217-283, 1997.

[81] Stephen L. Bloom and Zoltán Ésik. The equational logic of fixed points (tutorial). Theor. Comput. Sci., 179(1-2):1-60, 1997.

[82] Stephen L. Bloom and Zoltán Ésik. Fixed-point operations on CCC's. part I. Theor. Comput. Sci., 155(1):1-38, 1996.

[83] Stephen L. Bloom and Zoltán Ésik. Free shuffle algebras in language varieties. Theor. Comput. Sci., 163(1\&2):55-98, 1996.

[84] Zoltán Ésik. Definite tree automata and their cascade compositions. Publ. Math. Debrecen, 48:243-261, 1996.

[85] Stephen L. Bloom and Zoltán Ésik. Some equational laws of initiality in 2CCC's. Int. J. Found. Comput. Sci., 6(2):95-118, 1995.

[86] Zoltán Ésik and László Bernátsky. Equational properties of Kleene algebras of relations with conversion. Theor. Comput. Sci., 137(2):237-251, 1995.

[87] Stephen L. Bloom, Zoltán Ésik, and Gheorghe Stefanescu. Notes on equational theories of relations. Algebra Universalis, 33(1):98-126, 1995.

[88] Stephen L. Bloom, Zoltán Ésik, and Dirk Taubner. Iteration theories of synchronization trees. Inf. Comput., 102(1):1-55, 1993.

[89] Stephen L. Bloom and Zoltán Ésik. Erratum: Iteration algebras. Int. J. Found. Comput. Sci., 4(1):99, 1993.

[90] Stephen L. Bloom and Zoltán Ésik. Matrix and matricial iteration theories, part I. J. Comput. Syst. Sci., 46(3):381-408, 1993.

[91] Stephen L. Bloom and Zoltán Ésik. Matrix and matricial iteration theories, part II. J. Comput. Syst. Sci., 46(3):409-439, 1993. 
[92] Stephen L. Bloom and Zoltán Ésik. Equational axioms for regular sets. Mathematical Structures in Computer Science, 3(1):1-24, 1993.

[93] Stephen L. Bloom and Zoltán Ésik. Iteration algebras. Int. J. Found. Comput. Sci., 3(3):245-302, 1992.

[94] Zoltán Ésik. Varieties of automata and transformation semigroups. Acta Math. Hung., 59:59-74, 1992.

[95] Zoltán Ésik. A note on isomorphic simulation of automata by networks of two-state automata. Discrete Applied Mathematics, 30(1):77-82, 1991.

[96] Stephen L. Bloom and Zoltán Ésik. Floyd-Hoare logic in iteration theories. J. ACM, 38(4):887-934, 1991.

[97] Zoltán Ésik. Results on homomorphic realization of automata by $\alpha_{0}$-products. Theor. Comput. Sci., 87(2):229-249, 1991.

[98] Pál Dömösi and Zoltán Ésik. Product hierarchies of automata and homomorphic simulation. Acta Cybern., 9(4):371-373, 1990.

[99] Zoltán Ésik. A note on the axiomatization of iteration theories. Acta Cybern., 9(4):375-384, 1990.

[100] Stephen L. Bloom, Zoltán Ésik, and Ernest G. Manes. A Cayley theorem for Boolean algebras. The American Mathematical Monthly, 97(9):831-833, 1990.

[101] Stephen L. Bloom and Zoltán Ésik. Equational logic of circular data type specification. Theor. Comput. Sci., 63(3):303-331, 1989.

[102] Zoltán Ésik and Ferenc Gécseg. A decidability result for homomorphic representation of automata by $\alpha_{0}$-products. Acta Math. Hung., 53(1-2):205-212, 1989.

[103] Zoltán Ésik and Ferenc Gécseg. On $\alpha_{1}^{\lambda}$-products of automata. Acta Sci. Math. Szeged, 53:245-253, 1989.

[104] Pál Dömösi and Zoltán Ésik. On the hierarchy of $\nu_{i}$-product. Acta Cybern., 8(3):253-257, 1988.

[105] Pál Dömösi and Zoltán Ésik. On homomorphic simulation of automata by $\alpha_{0}$-products. Acta Cybern., 8(4):315-323, 1988.

[106] Zoltán Ésik. Independence of the equational axioms for iteration theories. $J$. Comput. Syst. Sci., 36(1):66-76, 1988.

[107] Stephen L. Bloom and Zoltán Ésik. Varieties of iteration theories. SIAM J. Comput., 17(5):939-966, 1988. 
[108] Pál Dömösi and Zoltán Ésik. Critical classes for the $\alpha_{0}$-product. Theor. Comput. Sci., 61:17-24, 1988.

[109] Zoltán Ésik. On cycles of directed graphs. Periodica Math. Hung., 19:19-23, 1988.

[110] Zoltán Ésik and J. Virágh. A note on $\alpha_{0}^{*}$-products of aperiodic automata. Acta Cybern., 8(1):41-43, 1987.

[111] Zoltán Ésik. Loop products and loop-free products. Acta Cybern., 8(1):45-48, 1987.

[112] Zoltán Ésik. On isomorphic realization of automata with $\alpha_{0}$-products. Acta Cybern., 8(2):119-127, 1987.

[113] Zoltán Ésik and Ferenc Gécseg. On a representation of tree automata. Theor. Comput. Sci., 53:243-255, 1987.

[114] Pál Dömösi and Zoltán Ésik. On homomorphic simulation of automata by $\nu_{1}$-products. Papers on Automata Theory, IX:91-112, 1987.

[115] Zoltán Ésik. Varieties and general products of top-down algebras. Acta Cybern., 7(3):293-298, 1986.

[116] Zoltán Ésik and J. Virágh. On products of automata with identity. Acta Cybern., 7(3):299-311, 1986.

[117] Zoltán Ésik and Pál Dömösi. Complete classes of automata for the $\alpha_{0^{-}}$ product. Theor. Comput. Sci., 47(3):1-14, 1986.

[118] Zoltán Ésik and Ferenc Gécseg. On $\alpha_{0}$-products and $\alpha_{2}$-products. Theor. Comput. Sci., 48(3):1-8, 1986.

[119] Zoltán Ésik. Complete classes of automata for the $\alpha_{i}$-product. Found. Control Engrg., 11:95-107, 1986.

[120] Pál Dömösi and Zoltán Ésik. On homomorphic realization of automata with $\alpha_{0}$-products. Papers on Automata Theory, 8:63-97, 1986.

[121] Zoltán Ésik and Ferenc Gécseg. Type independent varieties and metric equivalence of tree automata. Fundam. Inform., 9:205-216, 1986.

[122] Zoltán Ésik. On the weak equivalence of Elgot's flow-chart schemata. Acta Cybern., 7(2):147-154, 1985.

[123] Stephen L. Bloom and Zoltán Ésik. Axiomatizing schemes and their behaviors. J. Comput. Syst. Sci., 31(3):375-393, 1985.

[124] Zoltán Ésik. Homomorphically complete classes of automata with respect to the $\alpha_{2}$-product. Acta Sci. Math. Szeged, 48:135-141, 1985. 
[125] Zoltán Ésik and Gyula Horváth. Pseudo varieties and $\alpha_{0}$-products. Papers on Automata Theory, 6:47-76, 1984.

[126] Zoltán Ésik. A note on kernel languages of programs (in hungarian). Alkalmazott Matematikai Lapok, 10:61-63, 1984.

[127] Zoltán Ésik and Ferenc Gécseg. General products and equational classes of automata. Acta Cybern., 6(3):281-284, 1983.

[128] Zoltán Ésik. On identities preserved by general products of algebras,. Acta Cybern., 6:285-289, 1983.

[129] Zoltán Ésik. Decidability results concerning tree transducers II. Acta Cybern., 6(3):303-314, 1983.

[130] Zoltán Ésik. Algebras of iteration theories. J. Comput. Syst. Sci., 27(2):291303, 1983.

[131] Zoltán Ésik and Gyula Horváth. The $\alpha_{2}$-product is homomorphically general. Papers on Automata Theory, 5:49-62, 1983.

[132] Zoltán Ésik. On homomorphic realization of monotone automata. Papers on Automata Theory, 5:63-76, 1983.

[133] Zoltán Ésik. On generalized iterative algebraic theories. Computational Linguistics and Computer Languages, 15:95-110, 1982.

[134] Zoltán Ésik and Balázs Imreh. Remarks on finite commutative automata. Acta Cybern., 5(2):143-146, 1981.

[135] Zoltán Ésik and Balázs Imreh. Subdirectly irreducible commutative automata. Acta Cybern., 5(3):251-260, 1981.

[136] Zoltán Ésik. Decidability results concerning tree transducers I. Acta Cybern., 5(1):1-20, 1980.

[137] Zoltán Ésik. Identities in iterative and rational algebraic theories. Computational Linguistics and Computer Languages, 14:183-207, 1980.

[138] Zoltán Ésik. On two problems of A. Salomaa. Acta Cybern., 2(4):299-306, 1976.

\section{Refereed conference articles}

[1] Arnaud Carayol and Zoltán Ésik. An analysis of the equational properties of the well-founded fixed point. In Chitta Baral, James P. Delgrande, and Frank Wolter, editors, Principles of Knowledge Representation and Reasoning: Proceedings of the Fifteenth International Conference, KR 2016, Cape Town, South Africa, April 25-29, 2016., pages 533-536. AAAI Press, 2016. 
[2] Zoltán Ésik. Ternary equational languages. In Yo-Sub Han and Kai Salomaa, editors, Implementation and Application of Automata - 21st International Conference, CIAA 2016, Seoul, South Korea, July 19-22, 2016, Proceedings, volume 9705 of Lecture Notes in Computer Science, pages 77-88. Springer, 2016.

[3] Zoltán Ésik and Szabolcs Iván. MSO-definable properties of Muller contextfree languages are decidable. In Cezar Câmpeanu, Florin Manea, and Jeffrey Shallit, editors, Descriptional Complexity of Formal Systems - 18th IFIP WG 1.2 International Conference, DCFS 2016, Bucharest, Romania, July 5-8, 2016. Proceedings, volume 9777 of Lecture Notes in Computer Science, pages 87-97. Springer, 2016.

[4] Zoltán Ésik, Uli Fahrenberg, and Axel Legay. *-continuous Kleene $\omega$-algebras. In Igor Potapov, editor, Developments in Language Theory - 19th International Conference, DLT 2015, Liverpool, UK, July 27-30, 2015, Proceedings., volume 9168 of Lecture Notes in Computer Science, pages 240-251. Springer, 2015.

[5] Zoltán Ésik. Equational properties of fixed point operations in Cartesian categories: An overview. In Giuseppe F. Italiano, Giovanni Pighizzini, and Donald Sannella, editors, Mathematical Foundations of Computer Science 2015 40th International Symposium, MFCS 2015, Milan, Italy, August 24-28, 2015, Proceedings, Part I, volume 9234 of Lecture Notes in Computer Science, pages 18-37. Springer, 2015.

[6] Zoltán Ésik. Equational properties of stratified least fixed points (extended abstract). In Valeria de Paiva, Ruy J. G. B. de Queiroz, Lawrence S. Moss, Daniel Leivant, and Anjolina Grisi de Oliveira, editors, Logic, Language, Information, and Computation - 22nd International Workshop, WoLLIC 2015, Bloomington, IN, USA, July 20-23, 2015, Proceedings, volume 9160 of Lecture Notes in Computer Science, pages 174-188. Springer, 2015.

[7] Zoltán Ésik, Uli Fahrenberg, and Axel Legay. *-continuous Kleene $\omega$-algebras for energy problems. In Ralph Matthes and Matteo Mio, editors, Proceedings Tenth International Workshop on Fixed Points in Computer Science, FICS 2015, Berlin, Germany, September 11-12, 2015., volume 191 of EPTCS, pages 48-59, 2015.

[8] Zoltán Ésik. A representation theorem for stratified complete lattices. In 11th Tbilisi Symp. Language, Logic and Computation, 21-26 Sept. 2015, pages 5658. Georgian Academy of Science, 2015.

[9] Zoltán Ésik and Panos Rondogiannis. Theorems on pre-fixed points of nonmonotonic functions with applications in logic programming and formal grammars. In Ulrich Kohlenbach, Pablo Barceló, and Ruy J. G. B. de Queiroz, editors, Logic, Language, Information, and Computation - 21st International 
Workshop, WoLLIC 2014, Valparaíso, Chile, September 1-4, 2014. Proceedings, volume 8652 of Lecture Notes in Computer Science, pages 166-180. Springer, 2014.

[10] Zoltán Ésik, Uli Fahrenberg, Axel Legay, and Karin Quaas. Kleene algebras and semimodules for energy problems. In Dang Van Hung and Mizuhito Ogawa, editors, Automated Technology for Verification and Analysis - 11th International Symposium, ATVA 2013, Hanoi, Vietnam, October 15-18, 2013. Proceedings, volume 8172 of Lecture Notes in Computer Science, pages 102117. Springer, 2013.

[11] Zoltán Ésik and Szabolcs Iván. Operational characterization of scattered MCFLs. In Marie-Pierre Béal and Olivier Carton, editors, Developments in Language Theory - 17th International Conference, DLT 2013, Marne-laVallée, France, June 18-21, 2013. Proceedings, volume 7907 of Lecture Notes in Computer Science, pages 215-226. Springer, 2013.

[12] Zoltán Ésik and Panos Rondogiannis. A fixed-point theorem for non-monotonic functions. In Panhellenic Logic - 9th Symposium, Athens, Greece, July 15-18, 2013. Proceedings, pages 43-48, 2013.

[13] Zoltán Ésik. On a connection between concurrency and formal languages. In Mathematical Foundation of Programming Semantics, MFPS29, New Orleans, 2013, volume 298 of ENTCS, page 143-164, 2013.

[14] Zoltán Ésik and Satoshi Okawa. On context-free languages of scattered words. In Hsu-Chun Yen and Oscar H. Ibarra, editors, Developments in Language Theory - 16th International Conference, DLT 2012, Taipei, Taiwan, August 14-17, 2012. Proceedings, volume 7410 of Lecture Notes in Computer Science, pages 142-153. Springer, 2012.

[15] Luca Aceto, Arnaud Carayol, Zoltán Ésik, and Anna Ingólfsdóttir. Algebraic synchronization trees and processes. In Artur Czumaj, Kurt Mehlhorn, Andrew M. Pitts, and Roger Wattenhofer, editors, Automata, Languages, and Programming - 39th International Colloquium, ICALP 2012, Warwick, UK, July 9-13, 2012, Proceedings, Part II, volume 7392 of Lecture Notes in Computer Science, pages 30-41. Springer, 2012.

[16] Arnaud Carayol and Zoltán Ésik. A context-free linear ordering with an undecidable first-order theory. In Jos C. M. Baeten, Thomas Ball, and Frank S. de Boer, editors, Theoretical Computer Science - 7th IFIP TC 1/WG 2.2 International Conference, TCS 2012, Amsterdam, The Netherlands, September 26-28, 2012. Proceedings, volume 7604 of Lecture Notes in Computer Science, pages 104-118. Springer, 2012.

[17] Zoltán Ésik and Szabolcs Iván. Hausdorff rank of scattered context-free linear orders. In David Fernández-Baca, editor, LATIN 2012: Theoretical Informatics - 10th Latin American Symposium, Arequipa, Peru, April 16-20, 2012. 
Proceedings, volume 7256 of Lecture Notes in Computer Science, pages 291302. Springer, 2012.

[18] Zoltán Ésik. Scattered context-free linear orderings. In Giancarlo Mauri and Alberto Leporati, editors, Developments in Language Theory - 15th International Conference, DLT 2011, Milan, Italy, July 19-22, 2011. Proceedings, volume 6795 of Lecture Notes in Computer Science, pages 216-227. Springer, 2011.

[19] Zoltán Ésik. Multi-linear iterative $K$-S-semialgebras. In Proceedings 27th Int. Conference on Mathematical Foundations of Programming Semantics, Carnegie Mellon University, May 2011, volume 276 of Electr. Notes Theor. Comput. Sci., pages 159-170, 2011.

[20] Zoltán Ésik. Residuated Park theories. In Proceedings of the Fifth International Conference on Topology, Algebra and Categories in Logic, Marseille, France, pages 37-40, 2011.

[21] Zoltán Ésik and Andreas Maletti. Simulations of weighted tree automata. In Proceedings of the 15th International Conference on Implementation and Application of Automata. Winnipeg, Canada, volume 6482 of Lecture Notes in Computer Science, pages 321-330. Springer, 2011.

[22] Zoltán Ésik and Werner Kuich. Axiomatizing rational series. In Proceedings of the 8th Panhellenic Logic Symposium. Ioannina, Greece, pages 30-34, 2011.

[23] Zoltán Ésik and Szabolcs Iván. On Müller context-free grammars. In Yuan Gao, Hanlin Lu, Shinnosuke Seki, and Sheng Yu, editors, Developments in Language Theory, 14th International Conference, DLT 2010, London, ON, Canada, August 17-20, 2010. Proceedings, volume 6224 of Lecture Notes in Computer Science, pages 173-184. Springer, 2010.

[24] Zoltán Ésik and Andreas Maletti. Simulation vs. equivalence. In Hamid R. Arabnia, George A. Gravvanis, and Ashu M. G. Solo, editors, Proceedings of the 2010 International Conference on Foundations of Computer Science, FCS 2010, July 12-15, 2010, Las Vegas, Nevada, USA, pages 119-124. CSREA Press, 2010.

[25] Zoltán Ésik and Andreas Maletti. Simulations of weighted tree automata. In Michael Domaratzki and Kai Salomaa, editors, Implementation and Application of Automata - 15th International Conference, CIAA 2010, Winnipeg, MB, Canada, August 12-15, 2010. Revised Selected Papers, volume 6482 of Lecture Notes in Computer Science, pages 321-330. Springer, 2010.

[26] Zoltán Ésik and Szabolcs Iván. Extended temporal logics on finite trees. In Masami Ito, Yuji Kobayashi, Kunitaka Shoji (eds.) Automata, Formal Languages, and Algebraic Systems. Kyoto, Japan, pages 47-62. World Scientific, 2010. 
[27] Zoltán Ésik. Representing small ordinals by finite automata. In Ian McQuillan and Giovanni Pighizzini, editors, Proceedings Twelfth Annual Workshop on Descriptional Complexity of Formal Systems, DCFS 2010, Saskatoon, Canada, 8-10th August 2010., volume 31 of EPTCS, pages 78-87, 2010.

[28] Zoltán Ésik, Werner Kuich, and Masami Ito. Linear languages of finite and infinite words. In Masami Ito, Yuji Kobayashi, Kunitaka Shoji (eds.) Automata, Formal Languages, and Algebraic Systems. Kyoto, Japan, pages 33-46. World Scientific, 2010.

[29] Stephen L. Bloom, Zoltán Ésik, and Werner Kuich. Cycle-free finite automata in partial iterative semirings. In Symeon Bozapalidis and George Rahonis, editors, Algebraic Informatics, Third International Conference, CAI 2009, Thessaloniki, Greece, May 19-22, 2009, Proceedings, volume 5725 of Lecture Notes in Computer Science, pages 1-12. Springer, 2009.

[30] Zoltán Ésik and Tamás Hajgató. Iteration Grove theories with applications. In Symeon Bozapalidis and George Rahonis, editors, Algebraic Informatics, Third International Conference, CAI 2009, Thessaloniki, Greece, May 19-22, 2009, Proceedings, volume 5725 of Lecture Notes in Computer Science, pages 227-249. Springer, 2009.

[31] Zoltán Ésik and Szabolcs Iván. Context-free languages of countable words. In Martin Leucker and Carroll Morgan, editors, Theoretical Aspects of Computing - ICTAC 2009, 6th International Colloquium, Kuala Lumpur, Malaysia, August 16-20, 2009. Proceedings, volume 5684 of Lecture Notes in Computer Science, pages 185-199. Springer, 2009.

[32] Stephen L. Bloom and Zoltán Ésik. Scattered algebraic linear orderings. In Ralph Matthes and Tarmo Uustalu, editors, 6th Workshop on Fixed Points in Computer Science: FICS 2009, pages 25-30, 2009.

[33] Zoltán Ésik, Yuan Gao, Guangwu Liu, and Sheng Yu. Estimation of state complexity of combined operations. In Cezar Câmpeanu and Giovanni Pighizzini, editors, 10th International Workshop on Descriptional Complexity of Formal Systems, DCFS 2008, Charlottetown, Prince Edward Island, Canada, July 1618, 2008., pages 168-181. University of Prince Edward Island, 2008.

[34] Zoltán Ésik. Iteration semirings. In Masami Ito and Masafumi Toyama, editors, Developments in Language Theory, 12th International Conference, DLT 2008, Kyoto, Japan, September 16-19, 2008. Proceedings, volume 5257 of Lecture Notes in Computer Science, pages 1-20. Springer, 2008.

[35] Zoltán Ésik and Szabolcs Iván. Games for temporal logics on trees. In Oscar H. Ibarra and Bala Ravikumar, editors, Implementation and Applications of Automata, 13th International Conference, CIAA 2008, San Francisco, California, USA, July 21-24, 2008. Proceedings, volume 5148 of Lecture Notes in Computer Science, pages 191-200. Springer, 2008. 
[36] Zoltán Ésik and Szabolcs Iván. Aperiodicity in tree automata. In Symeon Bozapalidis and George Rahonis, editors, Algebraic Informatics, Second International Conference, CAI 2007, Thessaloniki, Greece, May 21-25, 2007, Revised Selected and Invited Papers, volume 4728 of Lecture Notes in Computer Science, pages 189-207. Springer, 2007.

[37] Stephen L. Bloom and Zoltán Ésik. Regular and algebraic words and ordinals. In Till Mossakowski, Ugo Montanari, and Magne Haveraaen, editors, Algebra and Coalgebra in Computer Science, Second International Conference, CALCO 2007, Bergen, Norway, August 20-24, 2007, Proceedings, volume 4624 of Lecture Notes in Computer Science, pages 1-15. Springer, 2007.

[38] Zoltán Ésik and Gabriela Martín. An algebraic characterization of Wolper's logic. In Hamid R. Arabnia and Pei Li Zhou, editors, Proceedings of the 2007 International Conference on Foundations of Computer Science, FCS 2007, June 25-28, 2007, Las Vegas, Nevada, USA, pages 139-143. CSREA Press, 2007.

[39] Zoltán Ésik and Werner Kuich. Fixed points in semiring theory. In Michael Kunc and Alexander Okhotin, editors, Theory and Applications of Language Equations: Proceedings of the 1st International Workshop, pages 5-13, 2007.

[40] Stephen L. Bloom and Zoltán Ésik. Completing categorical algebras. In Gonzalo Navarro, Leopoldo E. Bertossi, and Yoshiharu Kohayakawa, editors, Fourth IFIP International Conference on Theoretical Computer Science (TCS 2006), IFIP 19th World Computer Congress, TC-1 Foundations of Computer Science, August 23-24, 2006, Santiago, Chile, volume 209 of IFIP, pages 231249. Springer, 2006.

[41] Zoltán Ésik. Cascade products and temporal logics on finite trees. In Proceedings of the Workshop on Algebraic Process Calculi: The First Twenty Five Years and Beyond, volume 162 of Electr. Notes Theor. Comput. Sci., pages 163-166, 2006.

[42] Zoltán Ésik. An algebraic characterization of the expressive power of temporal logics on finite trees, Part 1. In 1st International Conference on Algebraic Informatics, pages 53-78, 2005.

[43] Zoltán Ésik. An algebraic characterization of the expressive power of temporal logics on finite trees, Part 2. In 1st International Conference on Algebraic Informatics, pages 79-100, 2005.

[44] Zoltán Ésik. An algebraic characterization of the expressive power of temporal logics on finite trees, Part 3. In 1st International Conference on Algebraic Informatics, pages 101-110, 2005.

[45] Zoltán Ésik and Gabriela Martin. A note on Wolper's logic. In Workshop on Semigroups and Automata, volume 3580 of Lecture Notes in Computer Science, pages $61-68,2005$. 
[46] Zoltán Ésik and Werner Kuich. An algebraic generalization of $\omega$-regular languages. In Jirí Fiala, Václav Koubek, and Jan Kratochvíl, editors, Mathematical Foundations of Computer Science 2004, 29th International Symposium, MFCS 2004, Prague, Czech Republic, August 22-27, 2004, Proceedings, volume 3153 of Lecture Notes in Computer Science, pages 648-659. Springer, 2004 .

[47] Stephen L. Bloom and Zoltán Ésik. Axioms for regular words: Extended abstract. In Paritosh K. Pandya and Jaikumar Radhakrishnan, editors, FST TCS 2003: Foundations of Software Technology and Theoretical Computer Science, 23rd Conference, Mumbai, India, December 15-17, 2003, Proceedings, volume 2914 of Lecture Notes in Computer Science, pages 50-61. Springer, 2003.

[48] Zoltán Ésik and Pascal Weil. On logically defined recognizable tree languages. In Paritosh K. Pandya and Jaikumar Radhakrishnan, editors, FST TCS 2003: Foundations of Software Technology and Theoretical Computer Science, 23rd Conference, Mumbai, India, December 15-17, 2003, Proceedings, volume 2914 of Lecture Notes in Computer Science, pages 195-207. Springer, 2003.

[49] Zoltán Ésik. Extended temporal logic on finite words and wreath products of monoids with distinguished generators. In Masami Ito and Masafumi Toyama, editors, Developments in Language Theory, 6th International Conference, DLT 2002, volume 2450 of Lecture Notes in Computer Science, pages 43-58, 2003.

[50] Luca Aceto, Zoltán Ésik, and Anna Ingólfsdóttir. Equational axioms for probabilistic bisimilarity. In Hélène Kirchner and Christophe Ringeissen, editors, Algebraic Methodology and Software Technology, 9th International Conference, AMAST 2002, Saint-Gilles-les-Bains, Reunion Island, France, September 913, 2002, Proceedings, volume 2422 of Lecture Notes in Computer Science, pages 239-253. Springer, 2002.

[51] Zoltán Ésik and Hans Leiß. Greibach normal form in algebraically complete semirings. In Julian C. Bradfield, editor, Computer Science Logic, 16th International Workshop, CSL 2002, 11th Annual Conference of the EACSL, Edinburgh, Scotland, UK, September 22-25, 2002, Proceedings, volume 2471 of Lecture Notes in Computer Science, pages 135-150. Springer, 2002.

[52] Zoltán Ésik. Extended temporal logic on finite words and wreath product of monoids with distinguished generators. In Masami Ito and Masafumi Toyama, editors, Developments in Language Theory, 6th International Conference, DLT 2002, Kyoto, Japan, September 18-21, 2002, Revised Papers, volume 2450 of Lecture Notes in Computer Science, pages 43-58. Springer, 2002.

[53] Z. Ésik. The equational theory of fixed points with applications to generalized language theory. In Werner Kuich, Grzegorz Rozenberg, and Arto Salomaa, editors, Developments in Language Theory: 5th International Conference, DLT 
2001 Wien, Austria, July 16-21, 2001 Revised Papers, pages 21-36, Berlin, Heidelberg, 2002. Springer Berlin Heidelberg.

[54] Stephen L. Bloom and Zoltán Ésik. Unique, guarded fixed points in an additive setting (extended abstract). In Proceedings Category Theory and Computer Science, CTCS 2002, Ottawa, volume 69 of Electr. Notes Theor. Comput. Sci., pages 47-61, 2002.

[55] Zoltán Ésik and Werner Kuich. Conway-halbringe als grundlage für eine mathematische automatentheorie. In Ju.I. Schevtschenko S.I. Aleschnikov, S.Ju. Piljugin, editor, Doklady meschdunarodnogo matematitscheskogo seminara $k$ 140-letiju sodnja roschdenija Davida Gilberta iz Kenigsberga i 25-letiju matematitscheskogo fakulteta (Vorträge des internationalen mathematischen Seminars zum 140. Geburtstag David Hilberts aus Königsberg und zum 25 jährigen Jubiläum der mathematischen Fakultät, pages 240-246. Universität in Königsberg, 2002.

[56] Zoltán Ésik. The equational theory of fixed points with applications to generalized language theory. In Werner Kuich, Grzegorz Rozenberg, and Arto Salomaa, editors, Developments in Language Theory, 5th International Conference, DLT 2001, Vienna, Austria, July 16-21, 2001, Revised Papers, volume 2295 of Lecture Notes in Computer Science, pages 21-36. Springer, 2001.

[57] Zoltán Ésik and Zoltán L. Németh. Automata on series-parallel biposets. In Werner Kuich, Grzegorz Rozenberg, and Arto Salomaa, editors, Developments in Language Theory, 5th International Conference, DLT 2001, Vienna, Austria, July 16-21, 2001, Revised Papers, volume 2295 of Lecture Notes in Computer Science, pages 217-227. Springer, 2001.

[58] Luca Aceto, Zoltán Ésik, and Anna Ingólfsdóttir. Axiomatizing tropical semirings. In Furio Honsell and Marino Miculan, editors, Foundations of Software Science and Computation Structures, 4 th International Conference, FOSSACS 2001 Held as Part of the Joint European Conferences on Theory and Practice of Software, ETAPS 2001 Genova, Italy, April 2-6, 2001, Proceedings, volume 2030 of Lecture Notes in Computer Science, pages 42-56. Springer, 2001.

[59] Janusz A. Brzozowski, Zoltán Ésik, and Y. Iland. Algebras for hazard detection. In 31st IEEE International Symposium on Multiple-Valued Logic, ISMVL 2001, Warsaw, Poland, May 22-24, 2001, Proceedings, pages 3-14. IEEE Computer Society, 2001.

[60] Luca Aceto, Zoltán Ésik, and Anna Ingólfsdottir. Nonfinitely based tropical semirings. In Gaubert, S. : Loiseau, J. J. (eds.), editor, Proceedings of the Workshop on Max-Plus Algebra and Their Applications to Discrete-Event Systems : Theoretical Computer Science, and Optimization, August 27-29 2001, Prague, Czech Republic, pages 29-34. Elsevier Science, 2001. 
[61] Zoltán Ésik. Axiomatizing the least fixed point operation and binary supremum. In Peter Clote and Helmut Schwichtenberg, editors, Computer Science Logic, 14th Annual Conference of the EACSL, Fischbachau, Germany, August 21-26, 2000, Proceedings, volume 1862 of Lecture Notes in Computer Science, pages 302-316. Springer, 2000.

[62] Janusz A. Brzozowski and Zoltán Ésik. Hazard algebras (extended abstract). In Arto Salomaa, Derick Wood, and Sheng Yu, editors, A Half-Century of Automata Theory: Celebration and Inspiration, pages 1-19. World Scientific, 2000 .

[63] Stephen L. Bloom and Zoltán Ésik. Iteration algebras are not finitely axiomatizable (extended abstract). In Gaston H. Gonnet, Daniel Panario, and Alfredo Viola, editors, LATIN 2000: Theoretical Informatics, 4th Latin American Symposium, Punta del Este, Uruguay, April 10-14, 2000, Proceedings, volume 1776 of Lecture Notes in Computer Science, pages 367-376. Springer, 2000 .

[64] Zoltán Ésik. Iteration theories of Boolean functions. In Mogens Nielsen and Branislav Rovan, editors, Mathematical Foundations of Computer Science 2000, 25th International Symposium, MFCS 2000, Bratislava, Slovakia, August 28 - September 1, 2000, Proceedings, volume 1893 of Lecture Notes in Computer Science, pages 343-352. Springer, 2000.

[65] Luca Aceto, Zoltán Ésik, and Anna Ingólfsdóttir. On the two-variable fragment of the equational theory of the max-sum algebra of the natural numbers. In Horst Reichel and Sophie Tison, editors, STACS 2000, 17th Annual Symposium on Theoretical Aspects of Computer Science, Lille, France, February 2000, Proceedings, volume 1770 of Lecture Notes in Computer Science, pages 267-278. Springer, 2000.

[66] Zoltán Ésik. Free algebras for generalized automata and language theory. In Proceedings of Algebraic Systems : Formal Languages and Computation, RIMS Kokyuroku 1166, Kyoto University, 2000, pages 52-58, 2000.

[67] Stephen L. Bloom and Zoltán Ésik. There is no finite axiomatization of iteration theories. In Proceedings LATIN 2000, Punta del Este, Uruguay, volume 1776 of Lecture Notes in Computer Science, page 367-376. Springer-Verlag, 2000.

[68] Zoltán Ésik and Satoshi Okawa. Series and parallel operations on pomsets. In C. Pandu Rangan, Venkatesh Raman, and Ramaswamy Ramanujam, editors, Foundations of Software Technology and Theoretical Computer Science, 19th Conference, Chennai, India, December 13-15, 1999, Proceedings, volume 1738 of Lecture Notes in Computer Science, pages 316-328. Springer, 1999.

[69] Zoltán Ésik, Masami Ito, and Masashi Katsura. The equational theory of reversal. In Gaubert, S. : Loiseau, J. J. (eds.), editor, Proceedings of the 
International Workshop on Formal Languages and Computer Systems, Kyoto, March 18 - 211997 and the First International Conference on Semigroups and Algebraic Engineering, Aizu, 24 - 28 March 1997, pages 502-521. World Scientific, 1999.

[70] Zoltán Ésik. Axiomatizing the equational theory of regular tree languages (extended abstract). In Michel Morvan, Christoph Meinel, and Daniel Krob, editors, STACS 98, 15th Annual Symposium on Theoretical Aspects of Computer Science, Paris, France, February 25-27, 1998, Proceedings, volume 1373 of Lecture Notes in Computer Science, pages 455-465. Springer, 1998.

[71] Stephen L. Bloom, Anna Labella, Zoltán Ésik, and Ernest G. Manes. Iteration 2-theories: Extended abstract. In Michael Johnson, editor, Algebraic Methodology and Software Technology, 6th International Conference, AMAST '97, Sydney, Australia, December 13-17, 1997, Proceedings, volume 1349 of Lecture Notes in Computer Science, pages 30-44. Springer, 1997.

[72] Stephen L. Bloom and Zoltán Ésik. Research project, axiomatizing shuffle. In Trabajos seleccionados WAIT '97, Buenos Aires, pages 47-54. Sociedad Argentina de Informatica e Investogacion Operativa, 1997.

[73] Zoltán Ésik and Anna Labella. Equational properties of iteration in algebraically complete categories. In Wojciech Penczek and Andrzej Szalas, editors, Mathematical Foundations of Computer Science 1996, 21st International Symposium, MFCS'96, Cracow, Poland, September 2-6, 1996, Proceedings, volume 1113 of Lecture Notes in Computer Science, pages 336-347. Springer, 1996.

[74] Zoltán Ésik and Michael Bertol. Nonfinite axiomatizability of the equational theory of shuffle. In Zoltán Fülöp and Ferenc Gécseg, editors, Automata, Languages and Programming, 22nd International Colloquium, ICALP95, Szeged, Hungary, July 10-14, 1995, Proceedings, volume 944 of Lecture Notes in Computer Science, pages 27-38. Springer, 1995.

[75] Stephen L. Bloom and Zoltán Ésik. Free shuffle algebras in language varieties (extended abstract). In Ricardo A. Baeza-Yates, Eric Goles Ch., and Patricio V. Poblete, editors, LATIN '95: Theoretical Informatics, Second Latin American Symposium, Valparaíso, Chile, April 3-7, 1995, Proceedings, volume 911 of Lecture Notes in Computer Science, pages 99-111. Springer, 1995.

[76] Stephen L. Bloom and Zoltán Ésik. Nonfinite axiomatizability of shuffle inequalities. In Peter D. Mosses, Mogens Nielsen, and Michael I. Schwartzbach, editors, TAPSOFT'95: Theory and Practice of Software Development, 6th International Joint Conference CAAP/FASE, Aarhus, Denmark, May 22-26, 1995, Proceedings, volume 915 of Lecture Notes in Computer Science, pages 318-333. Springer, 1995. 
[77] Zoltán Ésik and László Bernátsky. Scott induction and equational proofs. In Mathematical Foundations of Programming Semantics '95, New Orleans, volume 1 of Electr. Notes Theor. Comput. Sci., pages 154-181, 1995.

[78] Stephen L. Bloom and Zoltán Ésik. Solving polynomial fixed point equations. In Igor Prívara, Branislav Rovan, and Peter Ruzicka, editors, Mathematical Foundations of Computer Science 1994, 19th International Symposium, MFCS'94, Kosice, Slovakia, August 22 - 26, 1994, Proceedings, volume 841 of Lecture Notes in Computer Science, pages 52-67. Springer, 1994.

[79] László Bernátsky, Stephen L. Bloom, Zoltán Ésik, and Gheorghe Stefanescu. Equational theories of relations and regular sets. In Masami Ito and Helmut Jürgensen, editor, Proceedings of the International Conference on Words, Languages and Combinatorics, II., pages 40-48. World Scientific, 1994.

[80] Stephen L. Bloom and Zoltán Ésik. Some quasi-varieties of iteration theories. In Stephen D. Brookes, Michael G. Main, Austin Melton, Michael W. Mislove, and David A. Schmidt, editors, Mathematical Foundations of Programming Semantics, 9th International Conference, New Orleans, LA, USA, April 7-10, 1993, Proceedings, volume 802 of Lecture Notes in Computer Science, pages 378-409. Springer, 1993.

[81] Stephen L. Bloom and Zoltán Ésik. Program correctness and matricial iteration theories. In Stephen D. Brookes, Michael G. Main, Austin Melton, Michael W. Mislove, and David A. Schmidt, editors, Mathematical Foundations of Programming Semantics, 7th International Conference, Pittsburgh, PA, USA, March 25-28, 1991, Proceedings, volume 598 of Lecture Notes in Computer Science, pages 457-476. Springer, 1991.

[82] Stephen L. Bloom and Zoltán Ésik. Iteration algebras (extended abstract). In Samson Abramsky and T. S. E. Maibaum, editors, TAPSOFT'91: Proceedings of the International Joint Conference on Theory and Practice of Software Development, Brighton, UK, April 8-12, 1991, Volume 1: Colloquium on Trees in Algebra and Programming (CAAP'91), volume 493 of Lecture Notes in Computer Science, pages 264-274. Springer, 1991.

[83] Stephen L. Bloom, Zoltán Ésik, and Dirk Taubner. Iteration theories of synchronization trees. In Semantics for Concurrency: Proceedings of the International BCS-FACS Workshop, Sponsored by Logic for IT (S.E.R.C.), 23-25 July 1990, University of Leicester, UK, pages 96-115, London, 1990. Springer London.

[84] Pál Dömösi, Zoltán Ésik, and Balázs Imreh. On product hierarchies of automata. In János Csirik, János Demetrovics, and Ferenc Gécseg, editors, Fundamentals of Computation Theory, International Conference FCT'89, Szeged, Hungary, August 21-25, 1989, Proceedings, volume 380 of Lecture Notes in Computer Science, pages 137-144. Springer, 1989. 
[85] Zoltán Ésik. An extension of the Krohn-Rhodes decomposition of automata. In Jürgen Dassow and Jozef Kelemen, editors, Machines, Languages, and Complexity, 5th International Meeting of Young Computer Scientists, Smolenice, Czechoslovakia, November 14-18, 1988, Proceedings, volume 381 of Lecture Notes in Computer Science, pages 66-71. Springer, 1988.

[86] Pál Dömösi and Zoltán Ésik. On homomorphic realization and homomorphic simulation of automata by $\alpha_{0}$-products. In Proceedings Conference on Automata, Languages and Programming Systems, Salgótarján, pages 89-98, 1988.

[87] Zoltán Ésik, Pál Dömösi, Ferenc Gécseg, and J. Virágh. Homomorphic realizations of automata with compositions. In Jozef Gruska, Branislav Rovan, and Juraj Wiedermann, editors, Mathematical Foundations of Computer Science 1986, Bratislava, Czechoslovakia, August 25-29, 1996, Proceedings, volume 233 of Lecture Notes in Computer Science, pages 299-307. Springer, 1986.

[88] Zoltán Ésik. Completeness results in automata theory. In Proceedings Conference on Automata, Languages and Programming Systems, Salgótarján, pages 110-122. Karl Marx Univ. of Economics, 1986.

[89] Zoltán Ésik and János Virágh. On $\lambda$-products of automata. In Proceedings 4th Hungarian Computer Sci. Conf, pages 79-89. Akadémiai Kiadó, 1986.

[90] Zoltán Ésik. On Elgot's flowchart schemes. In System Theoretical Aspects in Computer Science, Salgótarján, pages 99-102, 1982.

[91] Zoltán Ésik. An axiomatization of regular forests in the language of algebraic theories with iteration. In Ferenc Gécseg, editor, Fundamentals of Computation Theory, FCT'81, Proceedings of the 1981 International FCT-Conference, Szeged, Hungary, August 24-28, 1981, volume 117 of Lecture Notes in Computer Science, pages 130-136. Springer, 1981.

[92] Zoltán Ésik. On functional tree transducers. In Fundamentals of Computation Theory, pages 121-127, 1979.

[93] Zoltán Ésik. On decidability of injectivity of tree transformations. In Les arbres en algebre et en programmation, Lille, pages 107-133, 1978.

\section{Refereed articles in other edited volumes}

[1] Zoltán Ésik and Werner Kuich. On power series over a graded monoid. In Cristian S. Calude, Rusins Freivalds, and Kazuo Iwama, editors, Computing with New Resources - Essays Dedicated to Jozef Gruska on the Occasion of His 80th Birthday, volume 8808 of Lecture Notes in Computer Science, pages 49-55. Springer, 2014. 
[2] Zoltán Ésik. Partial Conway and iteration semiring-semimodule pairs. In Werner Kuich and George Rahonis, editors, Algebraic Foundations in Computer Science - Essays Dedicated to Symeon Bozapalidis on the Occasion of His Retirement, volume 7020 of Lecture Notes in Computer Science, pages 56-71. Springer, 2011.

[3] Zoltán Ésik and Tamás Hajgató. Kleene theorem in partial Conway theories with applications. In Werner Kuich and George Rahonis, editors, Algebraic Foundations in Computer Science - Essays Dedicated to Symeon Bozapalidis on the Occasion of His Retirement, volume 7020 of Lecture Notes in Computer Science, pages 72-93. Springer, 2011.

[4] Zoltán Ésik and Werner Kuich. A unifying Kleene theorem for weighted finite automata. In Cristian S. Calude, Grzegorz Rozenberg, and Arto Salomaa, editors, Rainbow of Computer Science - Dedicated to Hermann Maurer on the Occasion of His 70th Birthday, volume 6570 of Lecture Notes in Computer Science, pages 76-89. Springer, 2011.

[5] Zoltán Ésik and Werner Kuich. A semiring-semimodule generalization of $\omega$ context-free languages. In Juhani Karhumäki, Hermann A. Maurer, Gheorghe Paun, and Grzegorz Rozenberg, editors, Theory Is Forever, Essays Dedicated to Arto Salomaa on the Occasion of His 70th Birthday, volume 3113 of Lecture Notes in Computer Science, pages 68-80. Springer, 2004.

[6] Zoltán Ésik and Werner Kuich. Equational axioms for a theory of automata. In Carlos Martin-Vide, Victor Mitrana, and Gheorge Paun, editors, Formal Languages and Applications. (Studies in Fuzziness And Soft Computing 148), pages 183-196, 2004.

[7] Zoltán Ésik and Werner Kuich. A generation of Kozen's axiomatization of the equational theory of the regular sets. In Masami Ito, Gheorghe Paun, and Sheng Yu, editors, Words, Semigroups, and Transductions - Festschrift in Honor of Gabriel Thierrin, pages 99-114. World Scientific, 2001.

\section{Other scientific papers}

[1] S. Aleshnikov, J. Boltnev, Z. Ésik, S. Ishanov, and W. Kuich. Formal languages and automata VII: Formal tree series, Part 2. VESTNIK KALININGRADSKOGO GOSUDARSTVENNOGO UNIVERSITETA, 10:7-49, 2012.

[2] S. Aleshnikov, J. Boltnev, Z. Ésik, S. Ishanov, and W. Kuich. Formal languages and automata VII: Formal tree series, Part 1. VESTNIK KALININGRADSKOGO GOSUDARSTVENNOGO UNIVERSITETA, pages 5-32, 2012.

[3] Zoltán Ésik and Klaus Sutner. Stephen L. Bloom 1940-2010. Fundam. Inform., 109(4):369-381, 2011. 
[4] S. Aleshnikov, J. Boltnev, Z. Ésik, S. Ishanov, and W. Kuich. Formal languages and automata VI: $\omega$-algebraic systems and transducers. VESTNIK KALININGRADSKOGO GOSUDARSTVENNOGO UNIVERSITETA, 10:8$32,2010$.

[5] S. Aleshnikov, J. Boltnev, Z. Ésik, S. Ishanov, and W. Kuich. Formal languages and automata $\mathrm{V}$ : Conway semiring-semimodule pairs and finite automata. VESTNIK KALININGRADSKOGO GOSUDARSTVENNOGO UNIVERSITETA, pages 6-41, 2009.

[6] S. Aleshnikov, J. Boltnev, Z. Ésik, S. Ishanov, and W. Kuich. Formaljnyje jasyki i avtomaty IV: Transduktory i abstraktnyje semejstva. VESTNIK KALININGRADSKOGO GOSUDARSTVENNOGO UNIVERSITETA, pages 6-23, 2008.

[7] S. Aleshnikov, J. Boltnev, Z. Ésik, S. Ishanov, and W. Kuich. Formalnyje jasyki i avtomaty III.: Magazinnyje avtomaty i formalnyje stepennyje rjady. VESTNIK KALININGRADSKOGO GOSUDARSTVENNOGO UNIVERSITETA, pages $8-27,2006$.

[8] S. Aleshnikov, J. Boltnev, Z. Ésik, S. Ishanov, and W. Kuich. Formal languages and automata, part II: Continuous semirings and algebraic systems. VESTNIK KALININGRADSKOGO GOSUDARSTVENNOGO UNIVERSITETA, pages $19-45,2004$.

[9] S. Aleshnikov, J. Boltnev, Z. Ésik, S. Ishanov, and W. Kuich. Formal languages and automata I: Conway semirings and finite automata. VESTNIK KALININGRADSKOGO GOSUDARSTVENNOGO UNIVERSITETA, pages 7-38, 2003.

[10] Stephen L. Bloom and Zoltán Ésik. Two axiomatizations of a star semiring quasi-variety. Bulletin of the EATCS, 59, 1996.

[11] Stephen L. Bloom and Zoltán Ésik. Cayley iff Stone. Bulletin of the EATCS, 43:159-161, 1991.

[12] Stephen L. Bloom and Zoltán Ésik. Some varieties of iteration theories. Bulletin of the EATCS, 24:53-65, 1984. 